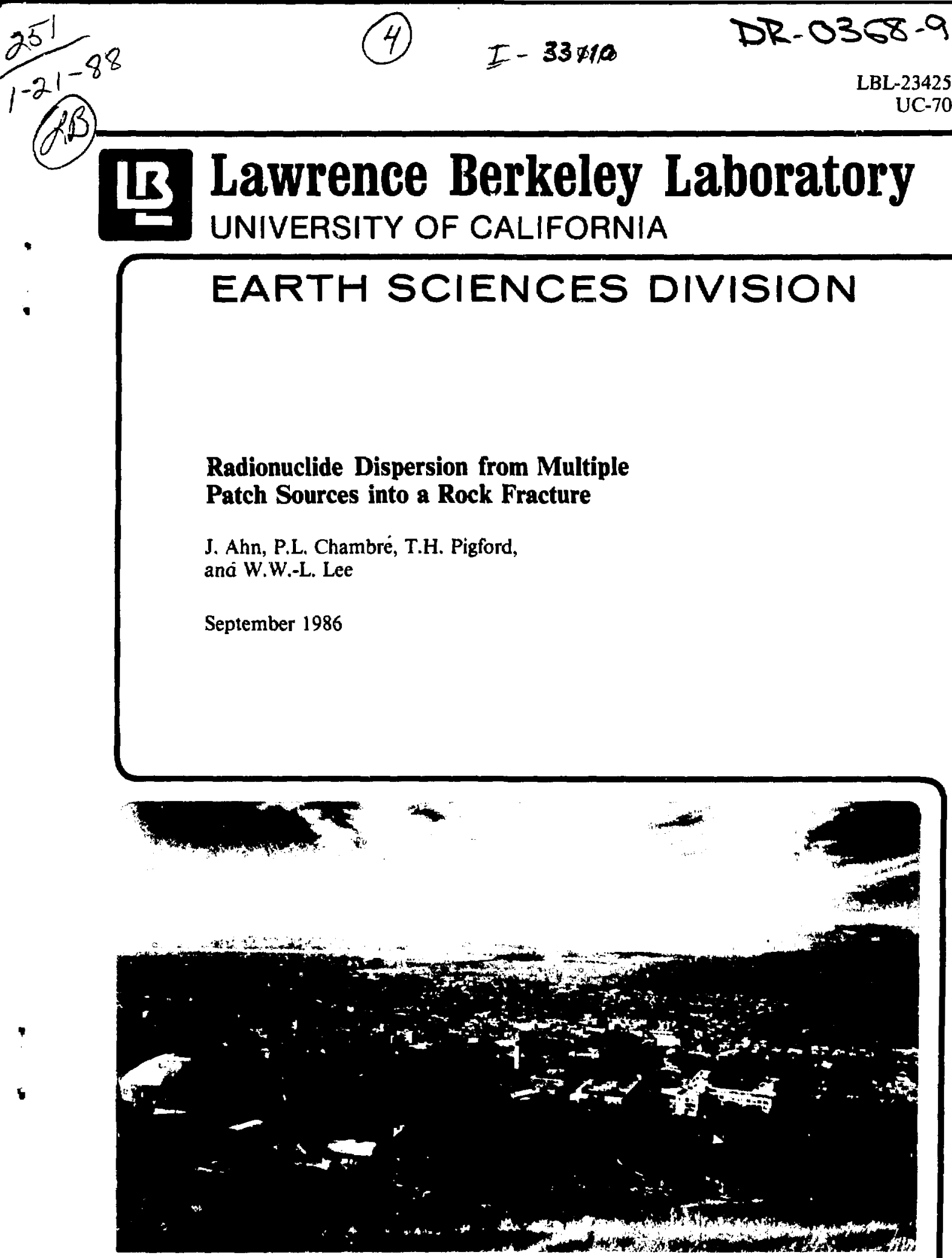


This report was prepared as an account of work sponsored by an agency of the United States

Government. Neither the United States Government nor any agency thereof, nor any of their employees, makes any warranty, express or implied, or assumes any legal liability or responsibility for the accuracy, completeness, or usefulness of any information, apparatus, product, or process disclowed, or represents that its use would not infringe privately owned rights. Refermanufacturer, or otherwise does not necaduct, process, or service by trade name, trademark. mendation, or fayoring by does not necessarily constitute or imply its endorsement, recomand opinions of authors the United States Government or any agency thereof. The views United Stutes Government or any asency theref not necessurily state or reflect thoee of the

\title{
RADIONUCLIDE DISPERSION FROM MULTIPLE PATCH SOURCES INTO A ROCK FRACTURE
}

\author{
J. Ahn, P. L. Chambre, T. H. Pigford, and W. W.-L. Lee \\ Earth Sciences Division, Lawrence Berkeley Laboratory \\ and \\ Department of Nuclear Engineering \\ University of California \\ Berkeley, CA 94720
}

\author{
September 1986
}

Work supported in part by U. S. Department of Energy contract DE-AC03-76SF00098 
The authors invite comments and would appreciate being notified of any errors in the report.

T. H. Pigford Department of Nuclear Engineering

University of California Berkeley, CA 94720

\section{ACKNOWLEDGEMENT}

This research was supported in part by the U. S. Department of Energy, Office of Civilian Radioactive Waste Management, Repository Technology Program. The conclualons of the authors are not neceseartly endorsed or approved by the U. S. Department of Energs. 
REPORT OUTLINE

\section{RADIONUCLIEE DISPERSION FROM MULTIPLE PATCH SOURCES INTO A ROCK FRACTURE}

1. Introduction and Summary

2. Conceptual Configuration of a Geological Repository and Formulation of the Problem 2.1 Conceptual Configuration of a Geological Repository and Physical System

2.2 The Transport Equations, Initial and Boundary Conditions

3. Transport of Radionuclides Released from a Single Patch Source

3.1 The Analytical Solutions for a Single Patch Source

3.2 Numerical Illustrations and Observations

4. Transport of Radionuclide Released from Multiple-Patch Sources

4.1 Formulation for Analysis

4.2 Comparison for Multiple-Patch Sources with an Infinite Source

4.3 Comparison for Multiple-Patch Sources with a Single Equivalent Source

4.4 Comparison for Transport in Fractured Media with Transport in Porous Media with Arrayed Point Sources

5. Concluding Remarks

6. References 


\section{Introduction and Summary}

This report presents results of an analytical study on hydrological transport of a radionuclide released from sources of finite areal extent into a planar fracture. The purposes of this work are to predict the space-time-dependent concentrations of a radionuclide which is released from multipie-patch (or area) sources and transported by advection and transverse dispersion in a planar fracture and by molecular diffusion in rock matrix, and to investigate the effects of transverse dispersion in the fracture.

In a previous report ${ }^{1}$, we presented the analytical solutions for concentrations of a radionuclide released from a source of infinite extent with zero and non-zero longitudinal dispersion in a fracture, and concluded that the effects of longitudinal dispersion in the fracture are negligible compared with those of advection. Although the analytical solutions for an infinite plane source, which neglect transverse dispersion in the fracture, are useful to obtain important insights into radionuclide transport in a fractured medium, these solutions will overestimate the concentrations at the far field. In a real waste repository waste packages will be arranged in an array, and thus we need to investigate how local transverse dispersion affects the radionuclide plumes produced from multiple sources of finite areal extent, and under what conditions we can use the infinite-source solution.

The solutions for the concentration of a radionuclide released from multiple-patch sources with transverse dispersion, similar to the current problem, were given by Kanki in a previous report ${ }^{2}$. Kanki's solutions, however, did not include sorption on the fracture wall, and the computer program coded by Kanki cannot calculate concentrations for large values of the transverse coordinate mainly because of an error which occurs at the subtraction of two error functions of very close arguments. In our solution we included the effects of sorption on the fracture walls. We coded a new computer program to avoid the numerical difficulties encountered in Kanki's program. 
We shall compare our results for radionuclides released into a planar fracture from a multiple-patch source to that for radionuclides released into continuous porous media from multiple point sources ${ }^{3}$.

With the new analytical solution we first investigated the time-dependency of radionuclide concentration for a single patch source for a band release. The analytical solution and numerical calculations show the following. Before the end of the leach time the timedependency is essentially the same as that of the infinite-source solution; the concentration in the fracture water decreases monotonically with downstream distance, and concentration in the rock-pore water decreases with distance from the fracture wall. After the leach time, back diffusion 4 causes the concentration profile in the fracture water to show a maximum along the water flow direction as well as a concentration maximum in the rock-pore water in the direction normal to the fracture piane near the source location. The difference between the single-patch solution and the infinite-source solution can be expressed by a time-nuclide-rockindependent, transverse-distance-dependent factor.

To investigate the effects of multiple-patch sources and local transverse dispersion, we calculate two ratios: (1) the ratio of radionuclide concentration resulting from multiplepatch sources to the concentration resulting from a single, infinite source of equivalent areal strength; and (2) the ratio of radionuclide concentration resulting from multiple-patch sources to that from a single, equivalent patch source, as a function of a distance parameter, defined as the downstream distance times the transverse dispersion coefficient divided by the groundwater velocity. We can identify three regions of the distance parameter, which hold for any nuclide, rock, and time: a near-field region where the effects of individual patch sources are significant; a mid-field region where patch sources, an equivalent single-patch source, and an infinite source all give identical results; and a far-field region where results for a single equivalent source and multiple-patch sources are identical. These three regions were also observed in the analyses of radionuclide transport through a porous medium, and the values of 
distance parameter which divide the three regions are very similar to those for the case of multiple patch sources releasing radionuclides into a rock fracture. 


\section{Conceptual Configuration of a Geological Repository and Formulation of the Problem}

\subsection{Conceptual Configuration of a Geological Repository and Physical System}

We consider a geologic repository with an array of point sources. The repository configuration is shown in Figure 1. We assume:

1) The waste canisters are arranged in a square planar array of overall dimensions $A^{2}$.

2) The waste consists of 10-year old waste from a pressurized water reactor, with heat generation rate of:

Spent fuel: $\mathbf{5 5 0} \mathrm{W} / \mathrm{assembly,} \mathrm{with} \mathrm{one} \mathrm{assembly} \mathrm{per} \mathrm{canister,}$

High level reprocessing waste: $1740 \mathrm{~W} /$ canister.

3) The areal loading of the repository is $20 \mathrm{~W} / \mathrm{m}^{2}$.

4) From assumptions 2 and 3 we will adopt for the present analysis typical container separation distance $d$ of $10 \mathrm{~m}$ and $5 \mathrm{~m}$. The approximate overall dimension $A$ of the repository is $900 \mathrm{~m}$.

This repository is assumed to intersect a planar fracture of infinite exient and of width

2b. To establish a nuclide-transport problem, we make the following assumptions relating to hydraulic properties of the system:

5) The fracture intersects with the repository so that the width of the cross-section of the repository becomes $A$.

6) Each waste container is exposed only to the fracture water and can be approximated as a planar patch source; the rest of the waste canister imbedded in the rock matrix is sound, so no nuclide is released directly to the rock matrix. The dimensions of an individual plane patch source are $2 a \times 2 b$, where $2 a$ is the width of a patch source which is assumed to be equal to the diameter of the waste canister and $2 b$ is the fracture width.

7) The aperture of the fracture is much smaller than its length. 


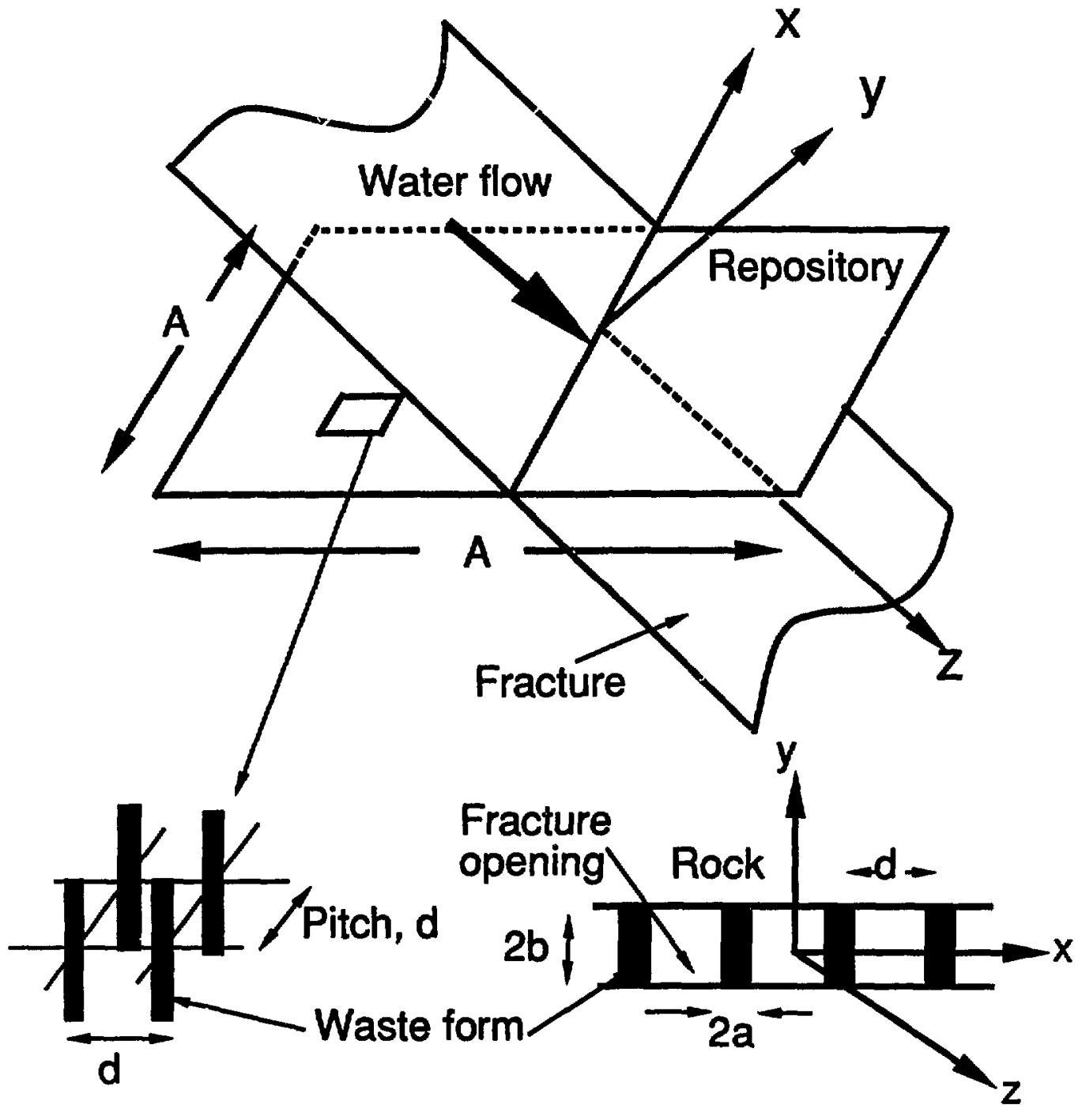

Figure 1 Conceptual configuration of a geological repository and a plane fracture of infinite extent. In the right-bottom figure waste forms are assumed to be plane patch sources of dimensions $2 a \times 2 b$. 
8) Diffusion and dispersion across the fracture width within the fracture assure complete mixing.

9) The permeability of the porous rock matrix is very low and transport in the rock matrix will be mainly by molecular diffusion. Water in the rock pores is stationary. The porosity of the rock matrix is $\varepsilon$.

10) Transport along the fracture is much faster than transport within the rock matrix.

By assumptions 5 and 6 multiple-patch sources are located within the width $A$ with a separation or pitch $d$. The number of patch sources is, therefore, calculated as $m=A / d$. Assumptions 7 and 8 provide the basis for a two-dimensional representation of mass transport along the fracture itself. Assumptions 9 and 10 furthermore provide the basis for taking the direction of mass flux in the porous rock matrix to be perpendicular to the fracture axis. This results in the simplification of the basically three-dimensional system to two orthogonal, coupled systems.

The following processes are to be considered (Figure 2): (a) advective transport in the fracture with velocity $v$, (b) mechanical dispersion and molecular diffusion within the fracture transverse to the water-flow direction, (c) matrix penetration by molecular diffusion from the fracture into the matrix with coefficient $D_{p}$, (d) sorption onto the fracture walls, (e) sorption onto the rock-pore surfaces in the rock matrix, and (f) radioactive decay without precursors (decay constant $\lambda$ ). The processes of mechanical dispersion and molecular diffusion in the fracture are lumped together as hydrodynamic dispersion with a single coefficient $D_{T}$. Sorption onto the fracture walls and onto the rock-pore surfaces within the rock matrix are considered separately here because of the possibility of differing chemical properties on the surfaces of the rock matrix. The longitudinal hydrodynamic dispersion in the fracture is neglected because our previous analyses ${ }^{1}$ showed advective transport in the fracture to be a more effective transport process. 


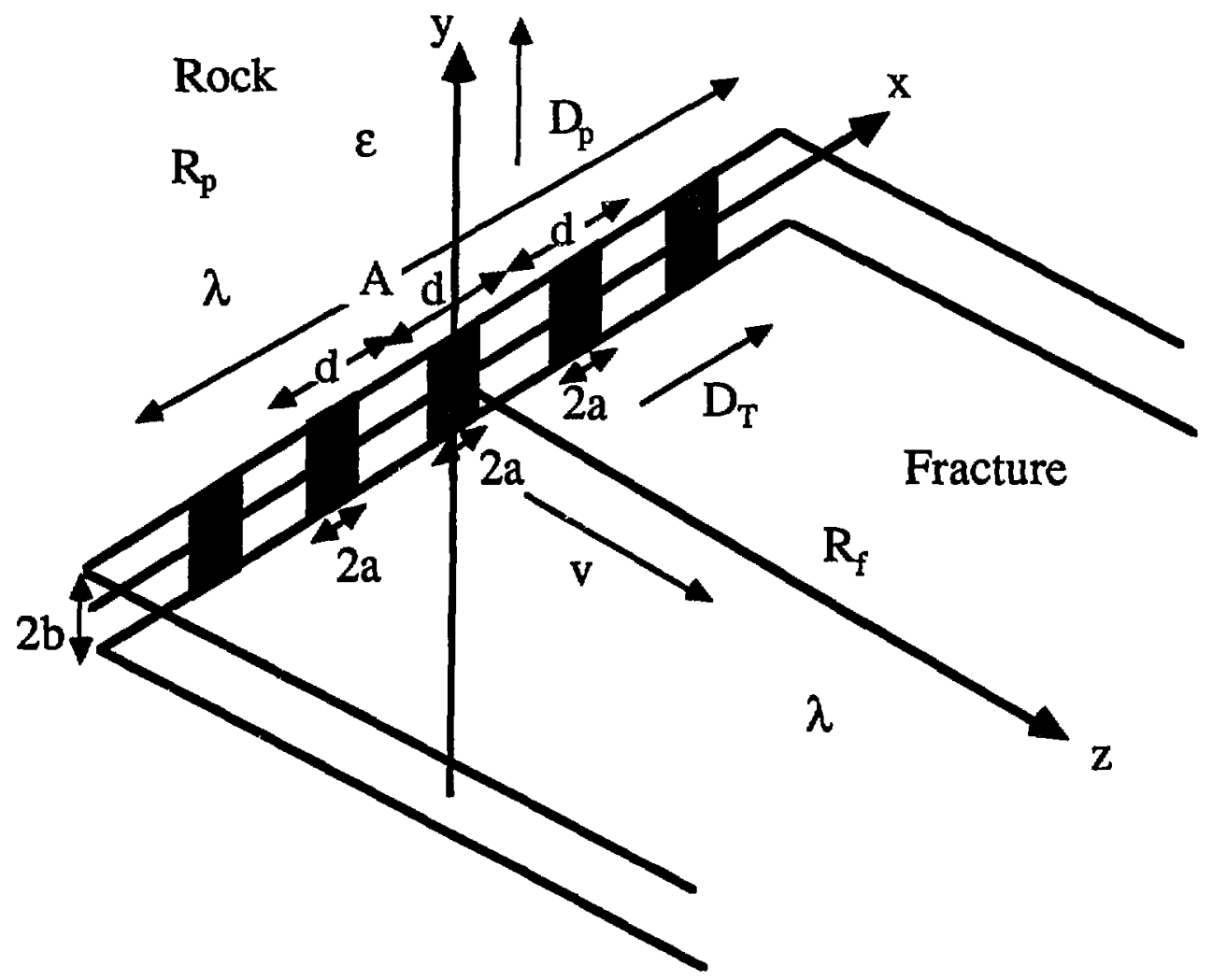

Figure 2 Geometry and physical processes to be considered in mathematical formulation (Definitions of quantities in the figures are given in the text.) 


\subsection{The Transport Equations, Initial and Boundary Conditions}

The transport processes in the system described above can be written in terms of two coupled differential equations: one for the fracture and one for the porous rock matrix. The coupling is provided by the continuity of flux $s$ and concentrations along the rock/fracture interface. The governing equation for the concentration in the water in the fracture can be obtained by balancing the total mass of the radionuclide in the fracture and by assuming a linear sorption equilibrium between the concentration in the water in the fracture and the concentration of the sorbed phase on the fracture walls:

$$
R_{f} \frac{\partial N}{\partial t}+v \frac{\partial N}{\partial z}-D_{T} \frac{\partial^{2} N}{\partial x^{2}}+R_{e} \lambda N+\frac{q}{b}=0, t>0, z>0,-\infty<x<\infty
$$

where

$N(x, z, t) \quad: \quad$ the concentration of the radionuclide in the water in the fracture at time $t$ at the location $(\mathrm{x}, \mathrm{z})\left[\mathrm{kg}\right.$-nuclide/ $\mathrm{m}^{3}$-fracture water],

$\mathbf{R}_{\mathrm{f}} \quad$ : dimensionless fracture retardation coefficient defined as:

$$
R_{\mathbf{f}}=1+\frac{\mathbf{K}_{\mathrm{f}}}{\mathrm{b}}
$$

$\mathbf{K}_{\mathrm{f}} \quad: \quad$ a sorption distribution coefficient [(kg-nuclide $/ \mathrm{m}^{2}$-fracture wall)/(kgnuclide/ $\mathrm{m}^{3}$-fracture water)].

$q(x, z, t)$ provides the coupling of two governing equations and is defined later. Note that $K a n k^{2}$ derived the solution for the special case of $R_{f}=1$.

The governing equation for the porous rock matrix can be obtained in a similar way by considering the mass balance for a strip of unit width, extending in the direction perpendicular to the fracture and by assuming a linear sorption equilibrium between the concentration in the rock-pore water and the concentraticn of the sorbzd phase on the pore surfaces: 


$$
R_{p} \frac{\partial M}{\partial t}-D_{p} \frac{\partial^{2} M}{\partial y^{2}}+R_{p} \lambda M=0, \quad y>b, z>0,-\infty<x<\infty, t>0,
$$

where

$\mathrm{M}(\mathrm{x}, \mathrm{y}, \mathrm{z}, \mathrm{t})$ : the concentration of the radionuclide in the rock-pore water [kg-nuclide/ $\mathrm{m}^{3}$-pore water],

$R_{\mathrm{p}} \quad$ : a dimensionless pore retardation coefficient defined as:

$$
R_{p}=1+\frac{a_{p} K_{p}}{\varepsilon}
$$

$\mathrm{K}_{\mathrm{p}} \quad$ : a sorption distribution coefficient $\left[\left(\mathrm{kg}\right.\right.$-nuclide $/ \mathrm{m}^{2}$-pore surface $) /(\mathrm{kg}$ nuclide/ $\mathrm{m}^{3}$-pore water $\left.)\right]$,

$a_{p} \quad:$ pore surface area per unit volume of rock $\left[\mathrm{m}^{2}\right.$-pore surface $/ \mathrm{m}^{3}$-rock].

We can now define one of the two coupling relations, i,e., flux continuity at the rock/fracture interface as:

$$
q(x, z, t)=-\left.\varepsilon D_{p} \frac{\partial M}{\partial y}\right|_{y=b}, \quad-\infty<x<\infty, \quad z>0, t>0
$$

We solve the governing equations (2.1) and (2.3) subject to the following initial and boundary conditions:

Initial Conditions:

$$
\begin{gathered}
\mathrm{N}(\mathrm{x}, \mathrm{z}, 0)=0, \quad-\infty<x<\infty, \quad z>0, \\
\mathrm{M}(\mathrm{x}, \mathrm{y}, \mathrm{z}, 0)=0, \quad-\infty<x<\infty, y>b, z>0 .
\end{gathered}
$$

Boundary Conditions:

$$
\begin{aligned}
& N(x, 0, t)=\varphi(t)[h(x+a)-h(x-a)],-\infty<x<\infty, t>0, \\
& N(x, \infty, t)=0, \quad-\infty<x<\infty, t>0, \\
& N( \pm \infty, z, t)=0, \quad z>0, t>0, \\
& M(x, b, z, t)=N(x, z, t), \quad-\infty<x<\infty, z>0, t>0 \text {, } \\
& M(x,+\infty, z, t)=0, \quad-\infty<x<\infty, z>0, t>0,
\end{aligned}
$$


where $\varphi(t)$ represents a time-dependent strength of a single-patch source and $h(\cdot)$ the Heaviside step function. Equation (2.8) assumes that the center of a single patch source of dimensions $2 a \times 2 b$ is located at the origin of the system. For multiple-patch sources we can superpose the solution for a single patch source. Also assumed is that within each patch source the time-dependency is uniform. To illustrate, consider a band release mode:

$$
\varphi(t)=N^{0} e^{-\lambda t}\{h(t)-h(t-T)\}
$$

where $N^{\circ}$ is the initial nuclide concentration in the fracture water at the source location $(z=0)$, $T$ a leach time.

Equation (2.11) is the remaining coupling relation of $N(x, z, t)$ and $M(x, y, z, t)$, i.e., the concentration continuity at the rock/fracture interface. 


\section{Transport of Radionuclide Released from a Single Patch Source}

\subsection{The Analytical Solution for a Single Patch Source}

We obtain the solution to the governing equations by taking Laplace transform of eqs. (2.1) and (2.3) with respect to $t$ and Fourier transform of the Laplace-transformed (2.1) with respect to $x$, with the aid of the initial and boundary conditions. The analytical solutions for $N(x, z, t)$ and $M(x, y, z, t)$, subject to side conditions (2.6) through (2.12), are:

$$
\begin{gathered}
N(x, z, t ; m=1)=N^{0} F(b, z, t) G(x ; \theta, a, 0),-\infty<x<\infty, t \geq 0, \\
M(x, y, z, t ; m=1)=N^{0} F(y, z, t) G(x ; \theta, a, 0),-\infty<x<\infty, y \geq b, z \geq 0, t \geq 0,(3,
\end{gathered}
$$
where

$$
\begin{aligned}
& F(y, z, t)=f(y, z, t)-e^{-\lambda T} f(y, z, t-T), \\
& f(y, z, t)=e^{-\lambda t} h(t-Z A) \text { erfc }\left[\frac{Z+B(y-b)}{2 \sqrt{t-Z A}}\right] \text {. } \\
& G\left(x ; \theta, a, x_{1}\right)=\frac{1}{2}\left[\operatorname{erf}\left(\frac{x-x_{1}+a}{2 \theta}\right)-\operatorname{erf}\left(\frac{x-x_{1}-a}{2 \theta}\right)\right] \text {, } \\
& Z=\frac{R_{f} z}{v A}, \quad A=\frac{b R_{f}}{E \sqrt{D_{p} R_{p}}}, \quad B=\sqrt{\frac{R_{p}}{D_{p}}}, \quad \theta=\sqrt{\frac{z \cdot D_{T}}{v}},
\end{aligned}
$$

$m$ the number of patch sources, and $x_{l}$ the coordinate of the transverse axis of the center of the patch source. The parameter $\theta^{2}$ is called a distance parameter, whose dimensions are $\left[\mathrm{m}^{2}\right]$. The distance parameter is a key parameter in evaluating the effect of the transverse dispersion, as will be shown in Chapter 4 . Because the center of the patch source is located at the origin of the system, we set $x_{1}=0$ in (3.1) and (3.2). Since the solutions to $N(x, z, t ; m)$ and $M(x$, $y, z, t ; m)$ have the same structure, any observation made for $M(x, y, z, t ; m)$ can be applied to $N(x, z, t ; m)$, and thus we will make use of the solution to $M(x, y, z, t ; m)$ for further analysis. 
In the analytical solutions we find that the effect of transverse dispersion appears in the function $G\left(x ; \theta, a, x_{1}\right)$. The rest of the solution, i.e., $N^{\circ} F(y, z, t)$ in (3.2), is identical to the solution for an infinite-plane sourcel:

$$
M^{\infty}(y, z, t)=N^{o} F(y, z, t) .
$$

As $a$ approaches infinity, $\mathrm{G}\left(\mathbf{x} ; \theta, \mathrm{a}, \mathrm{x}_{1}\right)$ becomes unity. Equation (3.7) can also be considered the solution for zexe transverse dispersion; if we take $D_{T}$ to zero, or $\theta$ to zero, $G\left(x ; \theta, a, x_{1}\right)$ also becomes unity.

In numerical evaluation of the anatyical solutions (3.1) and (3.2), we encountered a difficulty in the computer program developed by Kanki; for a large $x$ value and a comparably small $a$ value, the two error functions in (3.5) yield very close values, and on the subtraction a numerical error occurs because a digital computer can handle a linited number of significant digits. This difficulty was not recognized by Kanki. To avoid this, we return to the original definition of an error function expressed with an integral, and combine the two error functions in (3.5) into one integral, which is now evaluated numerically with the Gaussian quadrature method. For numerical integration we use the $\mathrm{NAG}^{5}$ subroutine D01AJF, which is a generalpurpose integrator.

\subsection{Numerical Illustrations and Observations}

With analytical soiutions (3.1) and (3.2), we now observe the time-dependency of concentra.ions and the effect of transverse dispersion on concentration profiles. To illustrate, we consider ${ }^{237} \mathrm{~Np}$ released from a single patch source with a band release. We conservatively assume that there is no sorption on the fracture walls $\left(R_{f}=1\right)$, but that in a porous rock matrix sorption is moderate $\left(R_{p}=100\right)$. Other parameters are set equal to previous reports 1 , 2 , and listed in each figure shown later in this chapter.

The concentration profiles of ${ }^{237} \mathrm{~Np}$ released from a single patch source along the transverse direction $x$ at various values of the downstream distance $z$ are shown in Figure 3. 


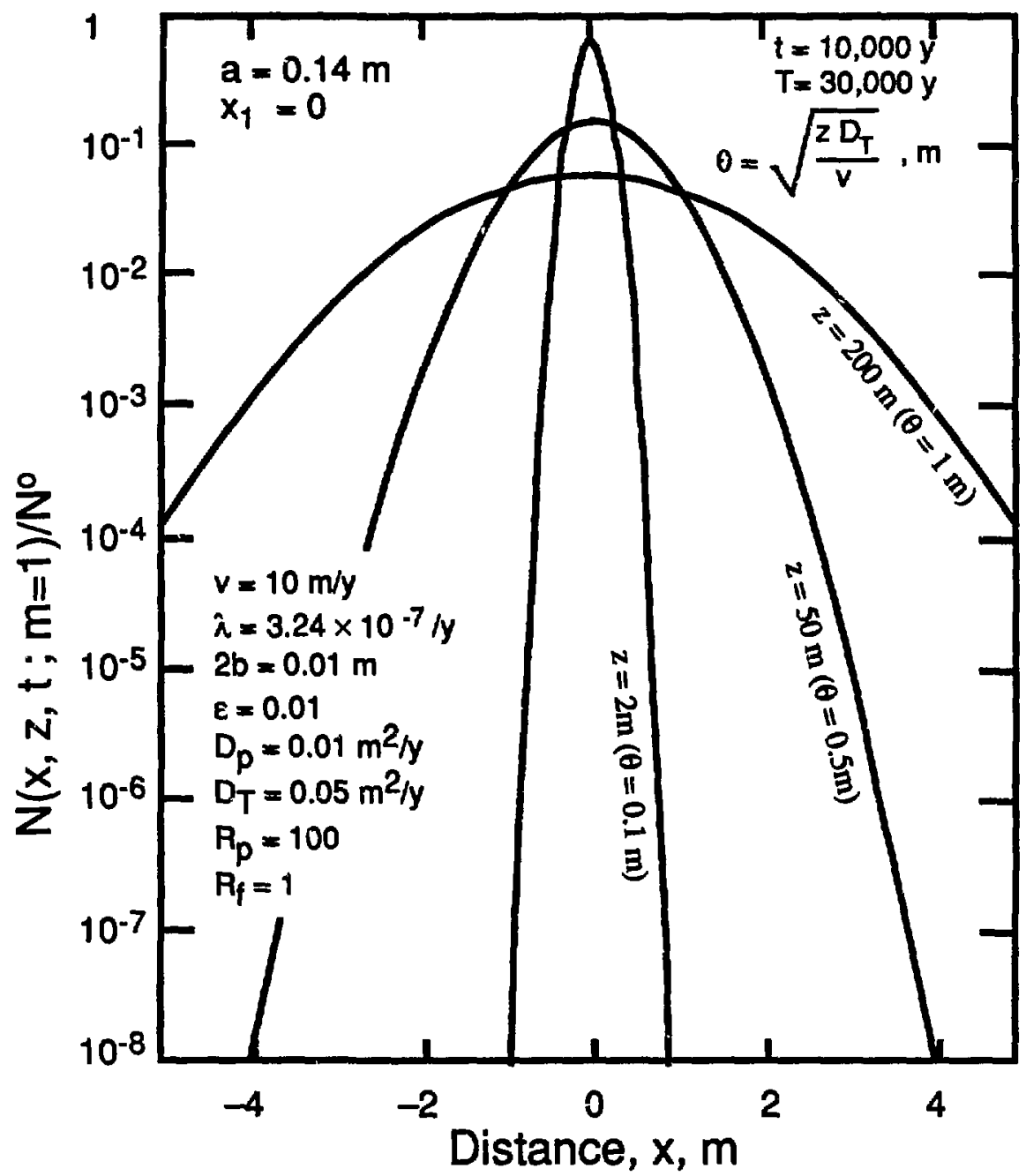

Figure 3 Concentration profiles of ${ }^{237} \mathrm{~Np}$ in the fracture in transverse direction, at $\mathrm{t}=10,000 \mathrm{y}$, a band release 


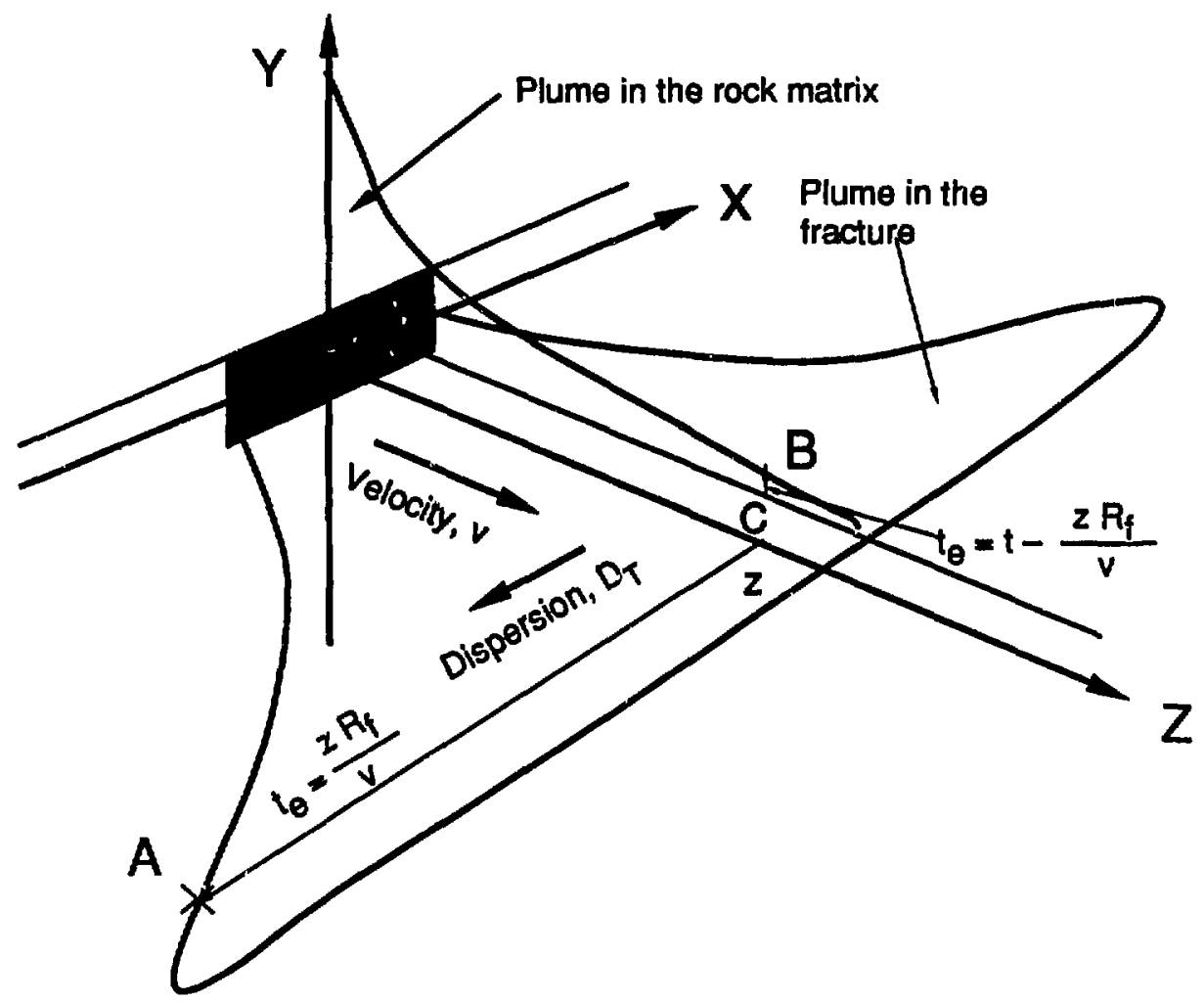

Figure 4 Difference in transverse dispersion along the $x$-axis and molecular diffusion in the rock matrix along the $y$-axis. Radionuclides take time $t_{e}=z R_{f} / v$ to reach point $A$ in the fracture by advection and transverse dispersion. Since advection and transverse dispersion take place together, the plume in the fracture shows a diverging shape. On the other hand, in order for radionuclides to ranoh point $P$ in the rock matrix, they must first reach point $\mathrm{C}$ in the fracture, and then by molecular diffusion radionuclides reacin point $B$ for time $t_{e}=t-z \cdot R_{f} / v$. Thus, at more distant goints from the source, the region affected by molecular diffusion becomes small. 
These concentrations are normalized to the initial concentration at the source. The transverse hydrodynamic dispersion coefficient $D_{T}$ is assumed to be $0.05 \mathrm{~m}^{2} / \mathrm{yr}$. Considering the value for molecular diffusion coefficient in the rock matrix $\left(D_{p}=0.01 \mathrm{~m}^{2} / y r\right)$ and the tortuosity in the rock matrix, we may say that the value chosen for $D_{\mathrm{T}}$ here neglects mechanical dispersion which is usually included in hydrodynamic dispersion together with molecular diffusion. By neglecting mechanical dispersion, we underestimate the effect of transverse hydrodynamic dispersion on fracture-flow transport, but by the end of this chapter we will see remarkable influence of the transverse dispersion even with the small value of $D_{T}=0.05 \mathrm{~m}^{2} / \mathrm{yr}$.

For a small downstream distance $z$ the concentration profiles in Figure 3 show a smaller dispersion path length and a steeper concentration gradient along the transverse axis $x$, and a larger peak value at $x=0$. As Kanki2 pointed out, this dispersion behaviour is quite different from the diffusion behaviour into the rock matrix in the y-direction. In the case of molecular diffusion into the rock matrix, a smaller diffusion path length and a greater gradient in the y-direction are observed at a larger downstream distance $z$. This difference was explained by introducing the concept of ar effective diffusion/dispersion time $t_{e}$ (see Figure 4); since the dispersion field in the $x$-direction moves with the water at the velocity $v / R_{f}$, the effective time for the transverse dispersion at a location $z$ can be determined by:

$$
t_{e}=\frac{z R_{f}}{v} \text {, }
$$

while the effective time for diffusion in the $y$-direction is given by:

$$
t_{e}=t-\frac{z R_{f}}{v},
$$

since the diffusion field in the rock pore is at rest. 


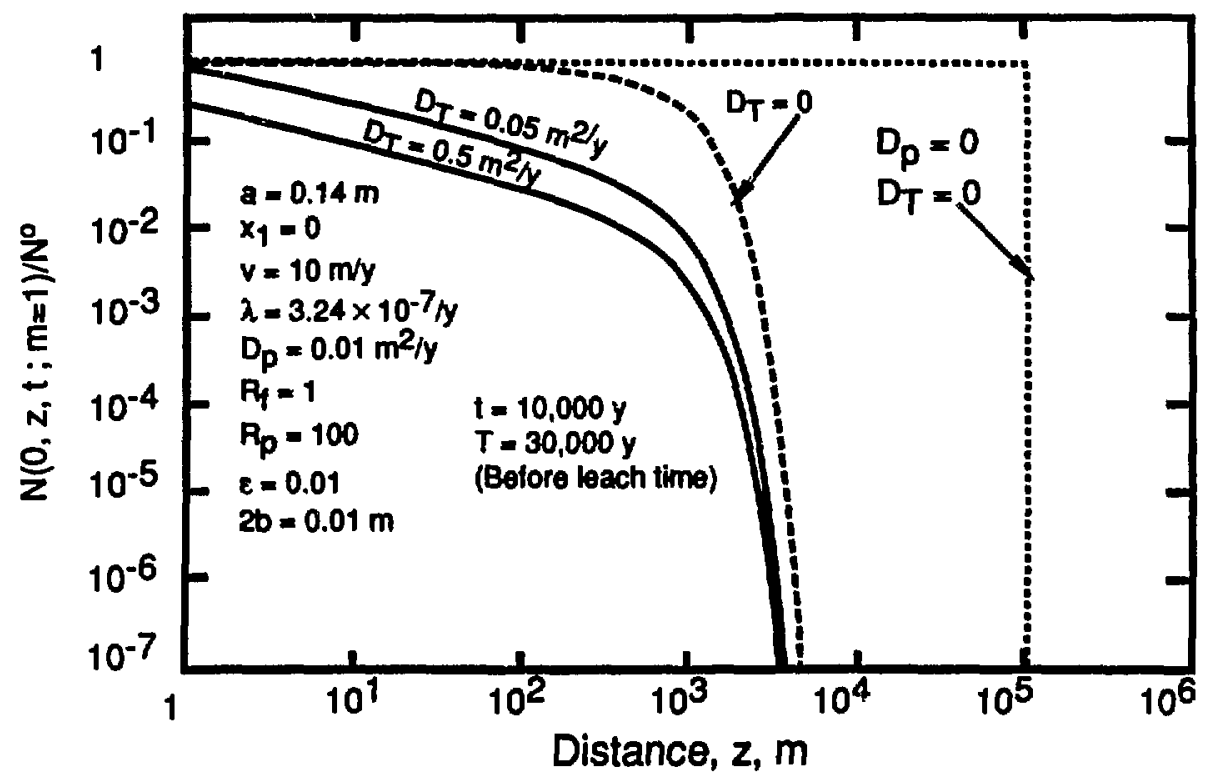

Figure 5 Effect of transverse dispersion on fracture flow transport, concentration profile of 237Np at $x=0$ in the fracture at $t=10,000 \mathrm{yr}$ (before the leach time $\mathrm{T}=30,000 \mathrm{yr}$ ) with three different transverse dispersion coefficients.

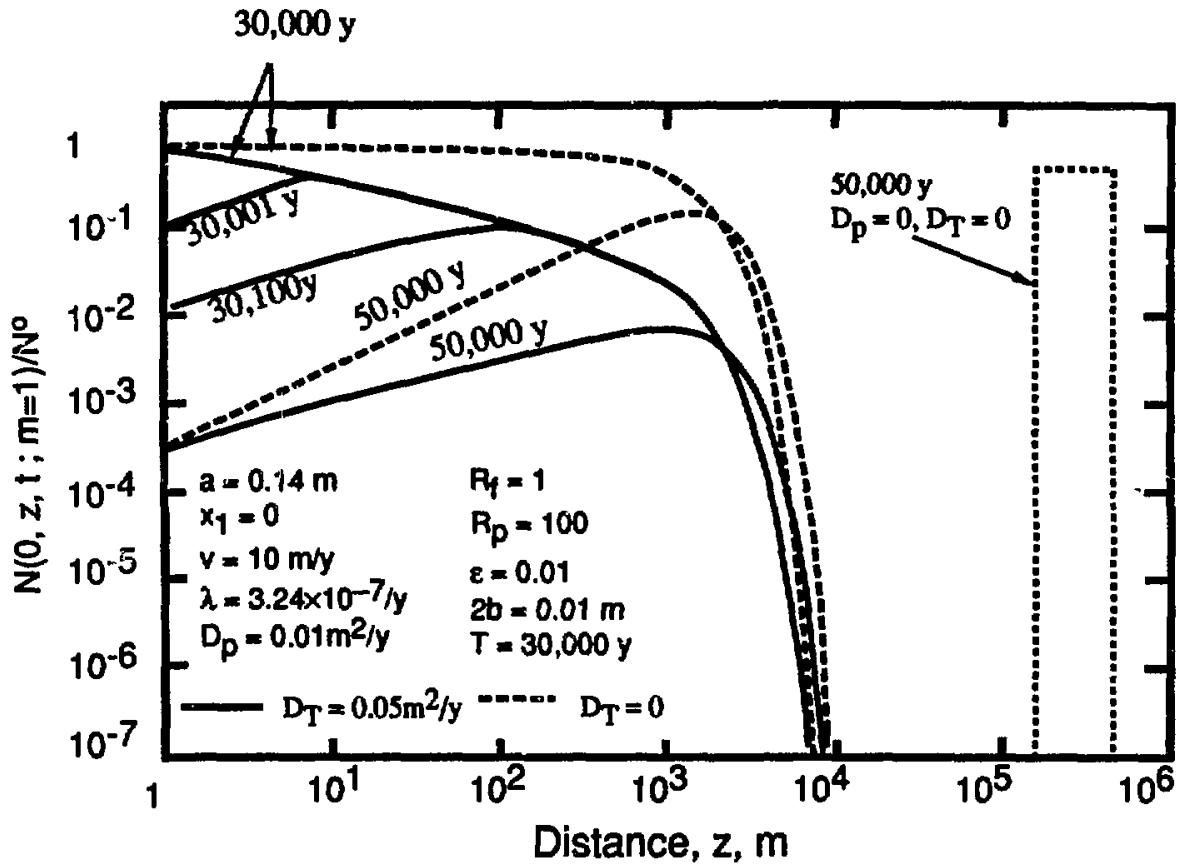

Figure 6 Concentration profiles of ${ }^{237} \mathrm{~Np}$ at $\mathrm{x}=0$ in the fracture at times after the leach time $\mathrm{T}=30,000 \mathrm{yr}$. 
The peak value shown in each profile of Figure 3 is attenuated by both the transverse dispersion in the $x$-direction and the molecular diffusion in the $y$-direction. To contrast these effects, we plot in Figure 5 the concentrations of ${ }^{237} \mathrm{~Np}$ along the $\mathrm{x}=0$ line in the fracture at $t$ $=10,000 \mathrm{yr}$ (before the end of the leaching period) for the following three cases: the concentrations with both the dispersion in the $\mathrm{x}$-direction and the molecular diffusion in the $y$ direction (solid lines), the concentrations with the molecular diffusion but without the transverse dispersion (a dashed line), and the concentrations without them (a broken line).

Without transverse dispersion or matrix penetration the leading edge travels as a square wave at the velocity $v / R_{f}$. If matrix penetration in the $y$-direction is considered, some of the radionuclide is removed from the fracture by matrix penetration, resulting in the retardation of nuclide movement along the fracture. If we consider both matrix penetration and transverse dispersion in the fracture, the concentrations are further attenuated along $z$. This combined effect is more pronounced for larger values of $D_{T}$. For instance, the concentration at $\mathrm{z}=1,000 \mathrm{~m}$ for $\mathrm{D}_{\mathrm{T}}=0.05 \mathrm{~m}^{2} / \mathrm{yr}$ is only about 1 percent of that without transverse dispersion. However, transverse dispersion has no significant effect in retarding the movement of the leading advection edge even for a large value of the dispersion coefficient. This is explained by the fact that around the leading advection edge the gradient due to transverse dispersion becomes quite low, whereas the gradient due to matrix penetration is very steep.

These observations can also be made for the profiles after the end of leaching period. Figure 6 shows the concentration profiles of ${ }^{237} \mathrm{~Np}$ at $\mathrm{x}=0$ in the fracture for $\mathrm{D}_{\mathrm{T}}=0.05$ $\mathrm{m}^{2} / \mathrm{yr}$ and $\mathrm{D}_{\mathrm{T}}=0$. As was observed at time before the leach time in Figure 5, the loci of the leading edge and the maximum are not retarded by transverse dispersion although the concentrations are attenuated by several orders of magnitude due to the transverse dispersion. 


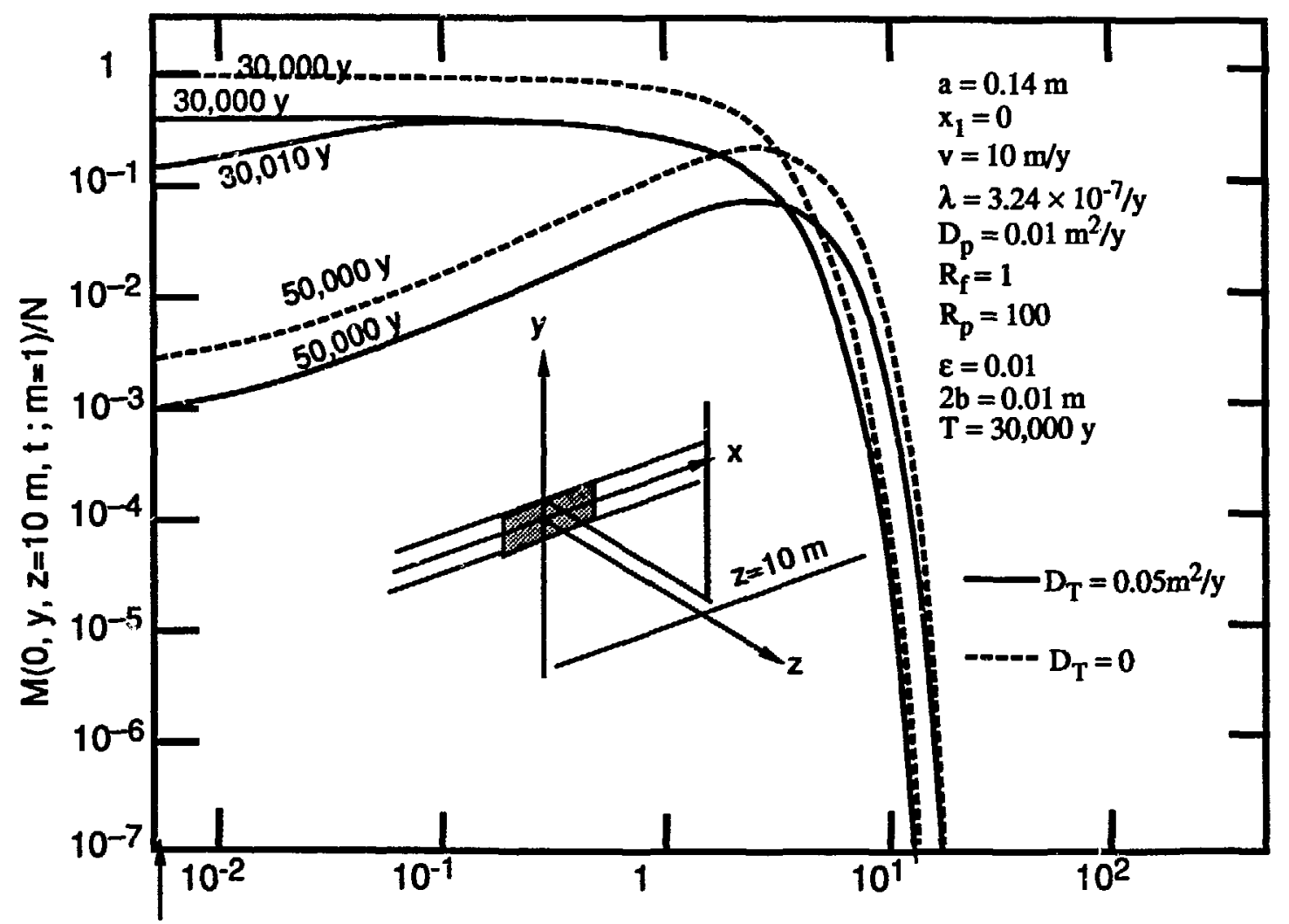

Fracture interface

$(y=0.005 \mathrm{~m})$

Distance, $y, m$

Figure 7 Time-dependent concentration profiles of ${ }^{237} \mathrm{~Np}$ at $(x, z)=(0,10 \mathrm{~m})$ in the rock matrix. 
The peak in the z-direction is due to back diffusion from the rock matrix. This phenomenon was first recognized and investigated in detail in a separate report $t^{4}$. We considered the following situation. The water in the rock pores is initially loaded throughout the entire porous rock matrix with a uniform concentration of a radionuclide. The initial concentration of the radionuclide in water in the fracture is zero. Radionuclide will move from water in the rock pores into water in the fracture due to a concentration gradient. Although the insights were obtained from the hypothetical model, we can use those for the explanation of the present case. Without molecular diffusion into the rock pores, the band-shaped concentration profile moves along the $\mathrm{z}$-direction after the leach time. On the other hand, with molecular diffusion and without transverse dispersion in the fracture, a trailing tail in the nearfield from the source in the broken-lined curve in Figure 6 results from uncontaminated water flowing into the fracture after the leach time, and the nuclide inside the rock matrix diffusing back to the fracture water due to a concentration gradient. However, beyond a certain point along the $\mathrm{z}$-direction this gradient changes to the opposite direction with the nuclide diffusing into the rock matrix. This occurs because as uncontaminated water proceeds in the fracture, the radionuclide concentration in the fracture water increases, and eventually becomes greater than the concentration in the rock matrix. The nuclide, therefore, again diffuses into the rock matrix. We can see in the Figure 7 that the nuclide diffuses back to the fracture at $t=50,000$ yr at $z=10 \mathrm{~m}$. Because of this behaviour nuclide movement in the fracture is significantly retarded compared with the case without matrix penetration; the leading edge proceeds only about $1,000 \mathrm{~m}$ in the period between $\mathrm{t}=30,000 \mathrm{yr}$ and $\mathrm{t}=50,000 \mathrm{yr}$ as shown with the two broken-lined curves in Figure 6.

Back diffusion is also observed in the case with the transverse dispersion in Figure 6. At $\mathrm{t}=30,001 \mathrm{yr}$, one year after the leach time, fresh water has intruded up to $10 \mathrm{~m}$ in the fracture because of the water velocity of $10 \mathrm{~m} / \mathrm{y}$ and no retardation in the fracture. Up to the $z$ $=10 \mathrm{~m}$ point the nuclide comes out to the fracture; beyond that point the nuclide in the fracture again diffuses into the rock matrix. At $\mathrm{t}=30,100 \mathrm{yr}, 100$ years after the leach time, although 
the front of the initially-uncontaminated water proceeds to $1,000 \mathrm{~m}$, the concentration profile in Figure 6 does not show the fresh-water front clearly at $\mathrm{z}=1,000 \mathrm{~m}$. This is because before the fresh water reaches the $1,000 \mathrm{~m}$ point, the concentration becomes greater than the concentration in the rock pores and the gradient at the interface switches direction. In Figure 7 we can confirm that the nuclide diffuses out to the fracture at $z=10 \mathrm{~m}$. Similar to the case without transverse dispersion, nuclide movement is retarded significantly after the leach time. This is evident by comparing the leading edges of $t=30,000 \mathrm{yr}$ and $t=50,000 \mathrm{yr}$ in Figure 6 .

The profiles for zero transverse dispersion and for non-zero transverse dispersion in Figure 7 seem parallel to each other, which means that the ratio of the two concentration is independent of $\%$, and even of time. If we take the ratio of the analytical solutions for these two cases, (3.2) and (3.7), the ratio becomes independent of time, nuclide, the distance into the rock matrix, and other rock-related parameters. We will observe the behaviour of multiple-patch sources by using this ratio with an appropriate definition of equivalent source strength in the following chapter. 


\section{Transport of Radionuclides Released from Multiple-Patch Sources}

In this chapter we present results of concentration fields of radionuclides released from multiple-patch sources, especially the effects of transverse dispersion. For multiplepatch scurces, we would expect to see the effects of individual sources near the sources. At some distance away, local dispersion wouid merge individual plumes so that an equivalent infinite plane source might give equally satisfactory results. At still larger distances the effect of transverse dispersion causes multiple-patch sources to hehave like a single, large patch source. To quantify these regions, we first derive the analytical solutions for multiple-patch sources by superposition of single-patch-source solutions shown in the previous chapter. We take the ratio of the concertration resulting from multiple-patch sources to the concentration resulting from an infinite source and the ratio of the concentration resulting from multiplepatch sources to the concentration resulting from a single patch of equivalent source strength. These ratios would predict the three regions.

\subsection{Formulation for Analysis}

The analytical solutions for multiple-patch sources are obtained by superposing the solutions for single-patch sources. The geometry studied was described in Section 2.1. Each patch source has an identical width $2 a$ with the same initial concentration $\mathrm{N}^{\circ}$ at $\mathrm{z}=0$, the same release characteristics, e.g., a band release, and is separated by a pitch $d$. All sources begin to release radioniclides at the same time. Then the solutions for multiple-patch sources are:

$$
M(x, y, z, t ; m)=N^{0} F(y, z, t) \sum_{k=1}^{m} G\left(x ; \theta, a, x_{k}\right),
$$

where the functions $F$ and $G$ are as defined in eqs. (3.4) and (3.5) respectively. $x_{k}$ is the location of the center of the $k$-th patch on the transverse axis $x$, and can be expressed as:

$$
x_{k}=d\left\{k-\frac{m+1}{2}\right\}, k=1,2, \ldots, m,
$$

where $m$ is the total number of patch sources. 
To obtain an equivalent source strength for an infinite source or an equivalent single patch source from single patch sources of width $2 a$ with the initial concentration $\mathrm{N}^{\circ}$ at $\mathrm{z}=0$ and separated by distance $d$, consider a material balance for the rate of total mass dissolution into the fracture water. For a patch source of initial total mass $W^{\circ}[\mathrm{kg}]$, distributed uniformly over the patch cross-sectional area $2 a \times 2 b$, and a leach time $T$ [yr], the rate of dissolution of total mass is $\mathrm{W}^{\circ} / \mathrm{T}[\mathrm{kg} / \mathrm{yr}]$. The unit source strength is:

$$
\frac{w^{0}}{T(2 a)(2 b)} n^{0} e^{-\lambda t}, \quad\left[\frac{k g}{m^{2} \cdot y}\right]
$$

where $n^{\circ}$ is the initial mass fraction of the nuclide in the waste (dumensionless). The unit source strength of an equivalent source of cross-sectional area $d \times 2 b$ is:

$$
\frac{w^{0}}{T(2 b) d} n^{0} e^{-\lambda t} . \quad\left[\frac{k g}{m^{2} \cdot y}\right]
$$

By a material balance at the source location, in the absence of axial dispersion, we can obtain the initial concentrations in the fracture water at the source location for the patch sovice of dimensions $2 a \times 2 b$ and the patch source of diminsions $d \times 2 b$ as:

$$
\begin{aligned}
& \frac{W^{0} n^{0}}{T}=(2 a)(2 t) v N^{0} \\
& \frac{W^{0} n^{0}}{T}=d(2 b) v N_{e q}^{0},
\end{aligned}
$$

where $\mathrm{N}_{\mathrm{eq}}^{\circ}$ is the initial concentration of the nuclide at the source location in the fracture water for the equivalent patch source ci width $d$. From (4.5) and (4.6), we can obtain a simple relation between $\mathrm{N}^{\circ}$ and $\mathrm{N}_{\mathrm{oq}}^{0}$ in : arms of the dimensions of the both sources:

$$
\frac{N^{0}}{N_{e q}^{0}}=\frac{d}{2 a} \text {. }
$$

We can now write the solution for an infinite source of strength equivalent to the multiple-patch sources located in a pitch $d$ by connecting infinitely many patch sources of width $d$ which produce initially the concentration $N_{e q}^{\circ}$ at $z=0$ : 


$$
M^{\infty}(y, z, t)=N_{e q}^{\circ} F(f, z, t)
$$

Similarly the solution for an equivalent single patch source which should be compared with the multiple-patch sources consisting of $m$ patches located in a pitch $d$ can be written as:

$$
M^{e q}(x, y, z, t)=N_{e q}^{\circ} F(y, z, t) G\left(x ; \theta, \frac{m d}{2}, 0\right) .
$$

In the following two sections we will observe the effect of transverse dispersion with the help of the ratio of (4.1) to (4.8) and the ratio of (4.1) to (4.9):

$$
\begin{aligned}
& \frac{M(x, y, z, t ; m)}{M^{\omega}(y, z, t)}=\frac{d}{2 a} \sum_{k=1}^{m} G\left(x ; \theta, a, x_{k}\right), \\
& \frac{M(x, y, z, t ; m)}{M^{e q}(x, y, z, t)}=\frac{d}{2 a} \frac{\sum_{k=1}^{m} G\left(x ; \theta, a, x_{k}\right)}{G\left(x ; \theta, \frac{m \cdot d}{2}, 0\right)},
\end{aligned}
$$

\subsection{Comparison for Multiple-Patsh Sources with an Infinite Source}

Figure 8 shows the relative nuclide concentration along the transverse coordinate, $x$, normal to the direction of the water flow, for the values of $\theta=0.2,0.4,1$ and $10 \mathrm{~m}$. The radionuclide source consists of 10 waste packages intersected by a fracture. The width of the overall source with 10 waste packages separated on $10 \mathrm{~m}$ centers is $100 \mathrm{~m}$. The centers of the patch sources are located at $\pm \mathrm{x}=\mathrm{d} / 2,3 \mathrm{~d} / 2, \ldots$, etc. For constant values of $D_{T}$ and $\nu, \theta$ is a downstream distance parameter. Figure 8 shows that for small values of $\theta$, the transverse concentration predicted by the muliple-patch-source model is quite different from that predicted by the infinite-source model. Near thesources, the local plumes are evident. At $\theta=$ $10 \mathrm{~m}$, local transverse dispersion has smeared the plumes together so that the two models give identical results. 


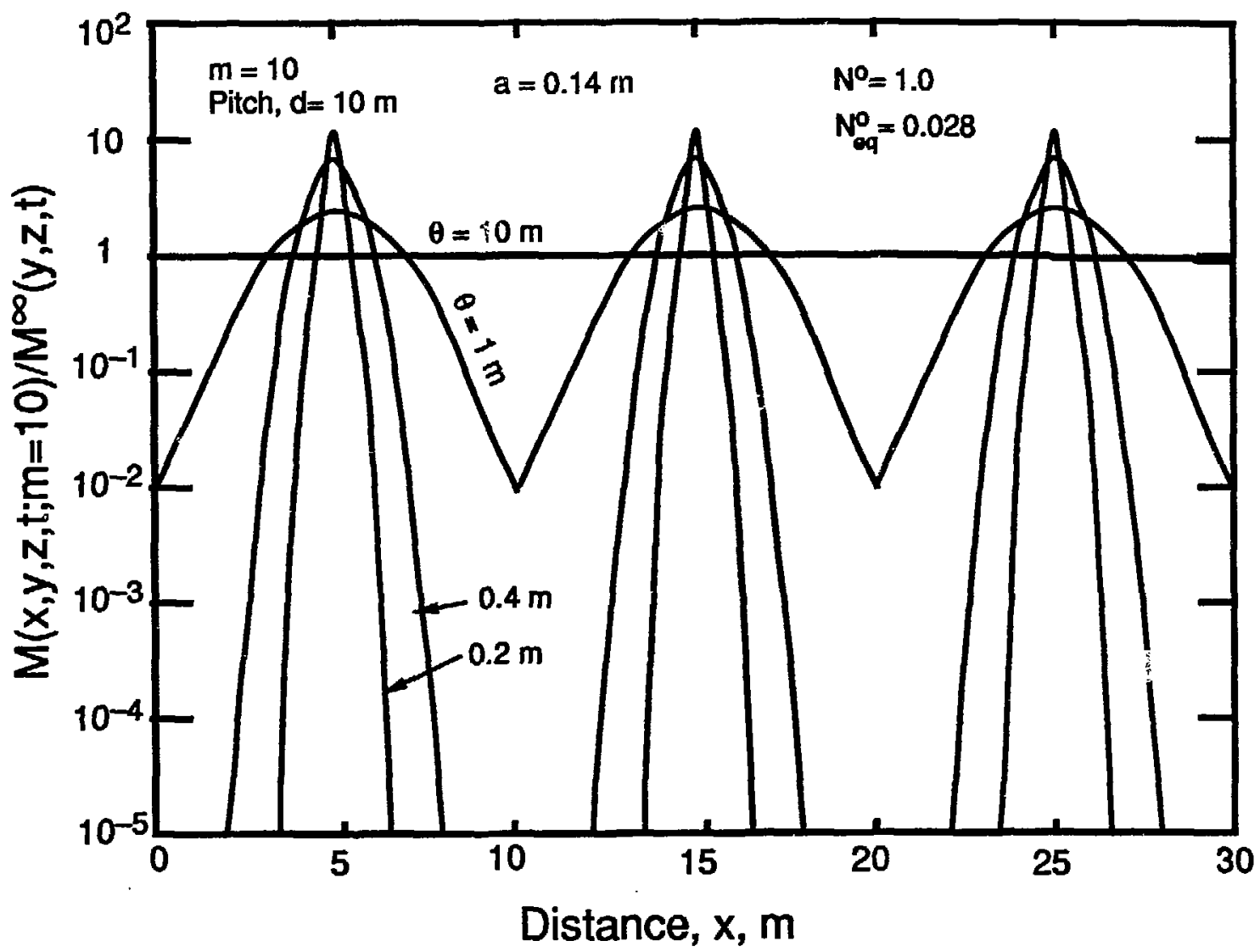

Figure 8 Distribution of the relative nuclide concentration (multiple-patch sources/ an infinite source) for four values of the distance parameter along the transverse coordinate $x$. 
The deviation from the infinite-source solution can be observed more clearly in Figure 9, which shows the relative nuclide concentration as a function of the distance parameter $\theta$ for a series of patch sources, with a source spacing of $d=10 \mathrm{~m}$ and for the number of patch sources varying 10 to 80 . The "peaks" are clearly seen in Figure 8, and the "valleys" can be seen for the $\theta=1 \mathrm{~m}$ curve in Figure 8. The near-field concentration ratios, for less than $\theta=3$ $m$, are shown for two branches. The peaks occur opposite the patch locations $(x=d / 2)$ and the valleys occur at the midpoint between adjacent sources $(x=0)$. These two branches coincide at greater than about $\theta=3 \mathrm{~m}$, where the multiple-patch concentration becomes identical to that from the infinite-source model. The concentration ratio remains at unity until a larger value of the distance parameter is reached, depending upon the number of patches. The multiple-patch concentration then becomes less than the infinite-source concentration, because of overall transverse dispersion. From Figure 9, we can observe three regions according to the distance parameter $\theta$ : (1) For $\theta$ less than about $3 \mathrm{~m}$, the multiple-patch concentration departs significantly from the infinite-source concentration due to discontinuities between discrete patch sources. (2) For $\theta$ between $3 \mathrm{~m}$ to 10 or $100 \mathrm{~m}$, depending upon the number of patches, these two concentration becomes identical because of local transverse dispersion. (3) For larger $\theta$ values, the multiple-patch concentration becomes less than the infinite-source concentration because of transverse dispersion into the region outside the projected $\mathrm{m}$-patch area. These observations are independent of radionuclide, time and rock.

In Figure 10 we study the effect of patch-source separation. By decreasing the source separation the plumes merge at a shorter downstream distance, as might be expected. The effect of overall transverse dispersion also occurs a shorter distance downstream. 


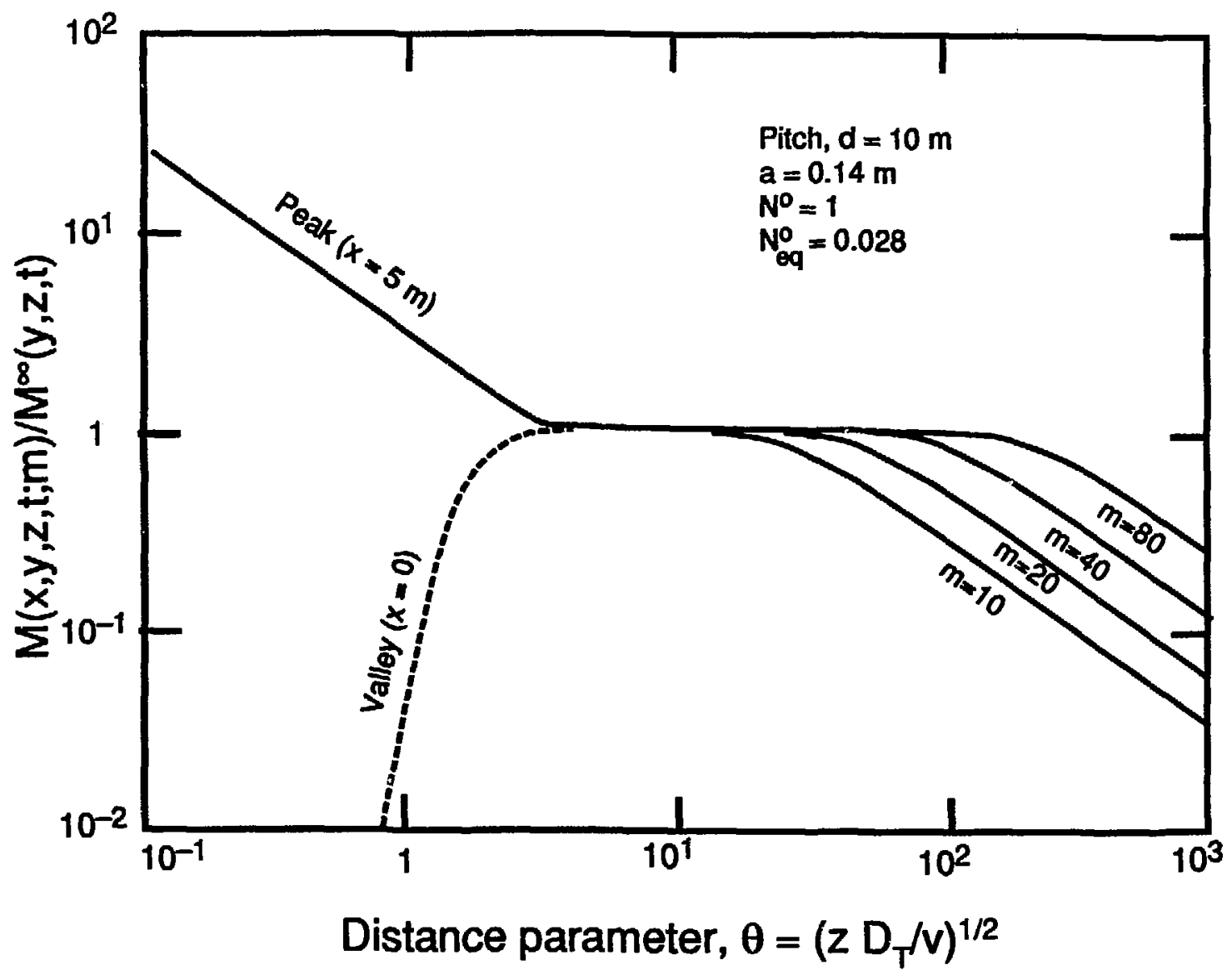

Figure 9 Effect of the size of multiple-patch sources on relative nuclide concentration profiles as a function of the distance parameter. For physical meanings of the peak and valley, refer to Figure 8. 


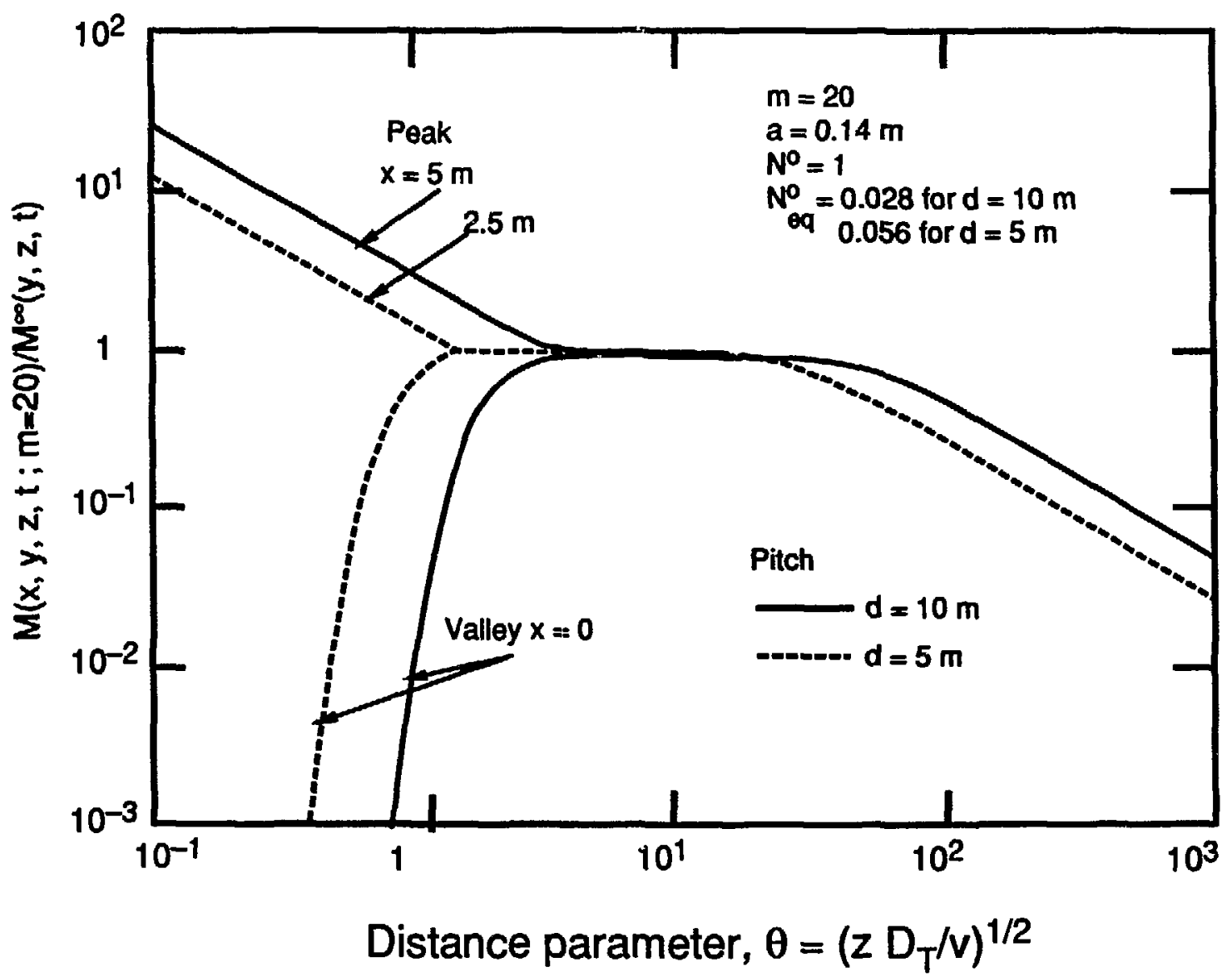

Figure 10 Effect of source separation on relative concentration profiles as a function of the distance parameter. 


\subsection{Comparison for Multiple-Patch Sources with a Single Equivalent Source}

In this section we compare the nuclide concentration fields predicted by a multiplepatch source model and a single equivalent-strength source. Figure 11 shows the relative nuclide concentration as a function of the distance parameter $\theta$ for 10 to 80 patch sources, spaced $5 \mathrm{~m}$ or $10 \mathrm{~m}$ apart. In Figure 11 the plumes-merge points are identical to those in Figure 10. However, there is no third region where transverse dispersion reduces the concentrations at the edge of the merged plume. This is because an equivalent patch source is created depending on the number of patch sources. The single equivalent patch source predicts identical concentrations as the multiple-patch source for $\theta$ greater than about $3 \mathrm{~m}$.

Figure 11 implies that for estimation of far-field concentrations we can consider the repository which actually consists of $m$ patch-sources as a large single-patch source of width $A$ (see Figure 1 for definition). The strength of that large single-patch source can be calculated by (4.7), as shown in Section 4.1. Thus we can investigate the effect of the size of the repository with the $: \mathrm{d}$ of an equivalent-single-patch-source solution. Figure 12 shows the relative concentration at $x=0$ as a function of the variable $\theta$ for three widths of the repository. Note that, as long as we follow the procedure for definig the equivalent source strength as shown in Section 4.1, this graph is valid for any set of source separation distance and dimension of waste packages. In the case of a relatively small repository of $A=200 \mathrm{~m}$, the relative concentration at $x=0$ begins to decrease at $\theta>30 \mathrm{~m}$. For example, if $v=10 \mathrm{~m} / \mathrm{y}$ and $D_{T}=0.05 \mathrm{~m}^{2} / y$, the effect of the transverse dispersion becomes important at $\mathrm{z}>1.8 \times 10^{5} \mathrm{~m}$. For the larger repository of $A=800 \mathrm{~m}$, the concentration profile in a normal plane through the center of the patch $(x=0)$ is identical with the concentration profile resulting from an infinite source up to $\theta=100 \mathrm{~m}$. 


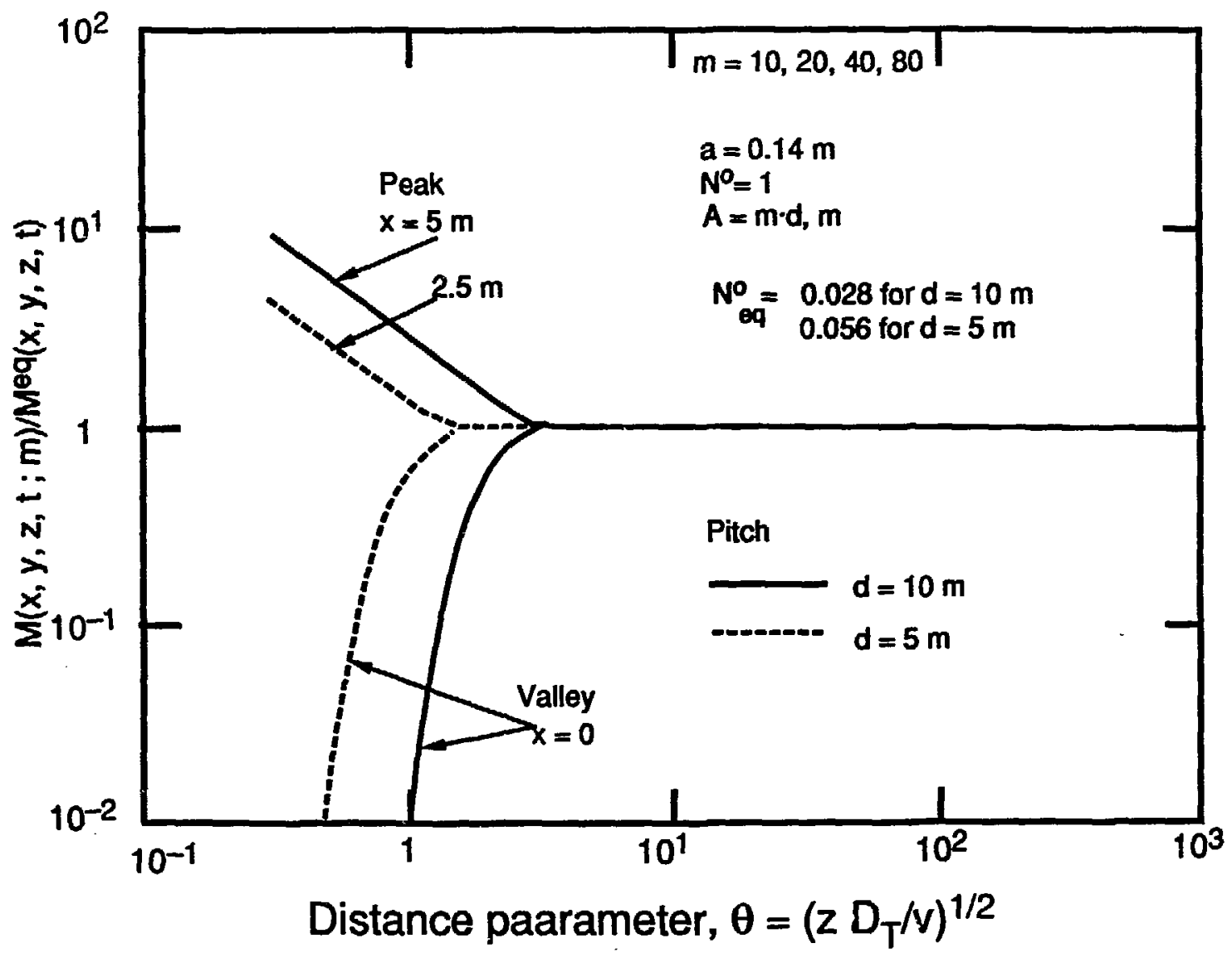

Figure 11 Relative nuclide concentration (multiple-patch sources/ an equivalent patch source) as a function of the distance parameter. 


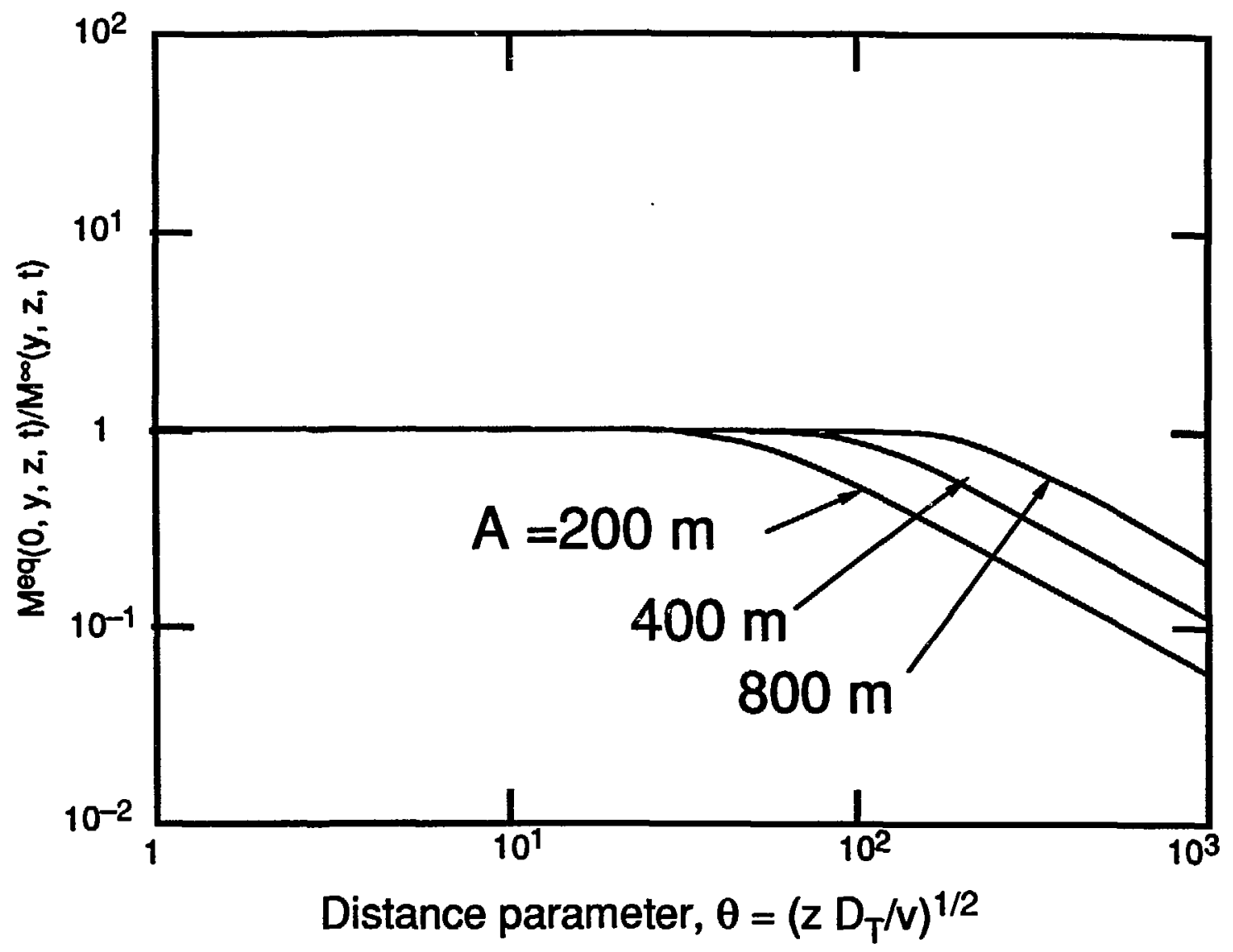

Figure 12 Effect of a repository size on the far-field concentration evaluated by the equivalent-single-patch solution 


\subsection{Comparison for Transport in Fractured Media with Transport in Porous Media with Arrayed Point Sources}

In Reference 3 we presented an analytical study of the effect of transverse dispersion on migration behaviour in one-dimensionai flow in a porous rock. The analyses were performed for the geometry shown in Figure 13. A two-dimensional repository of dimensions $A^{2}$ consists of an array of point sources in a pitch $d$. The porosity of the rock is $\varepsilon$. Water flows at velocity $v$ in the direction perpendicular to the repository plane. Linear sorption equilibrium is assumed in the porous rock, so nuclide movement is retarded. Dispersion transverse to the water flow is then two-dimensional, and transverse dispersion coefficient for each direction is assumed to be equal.

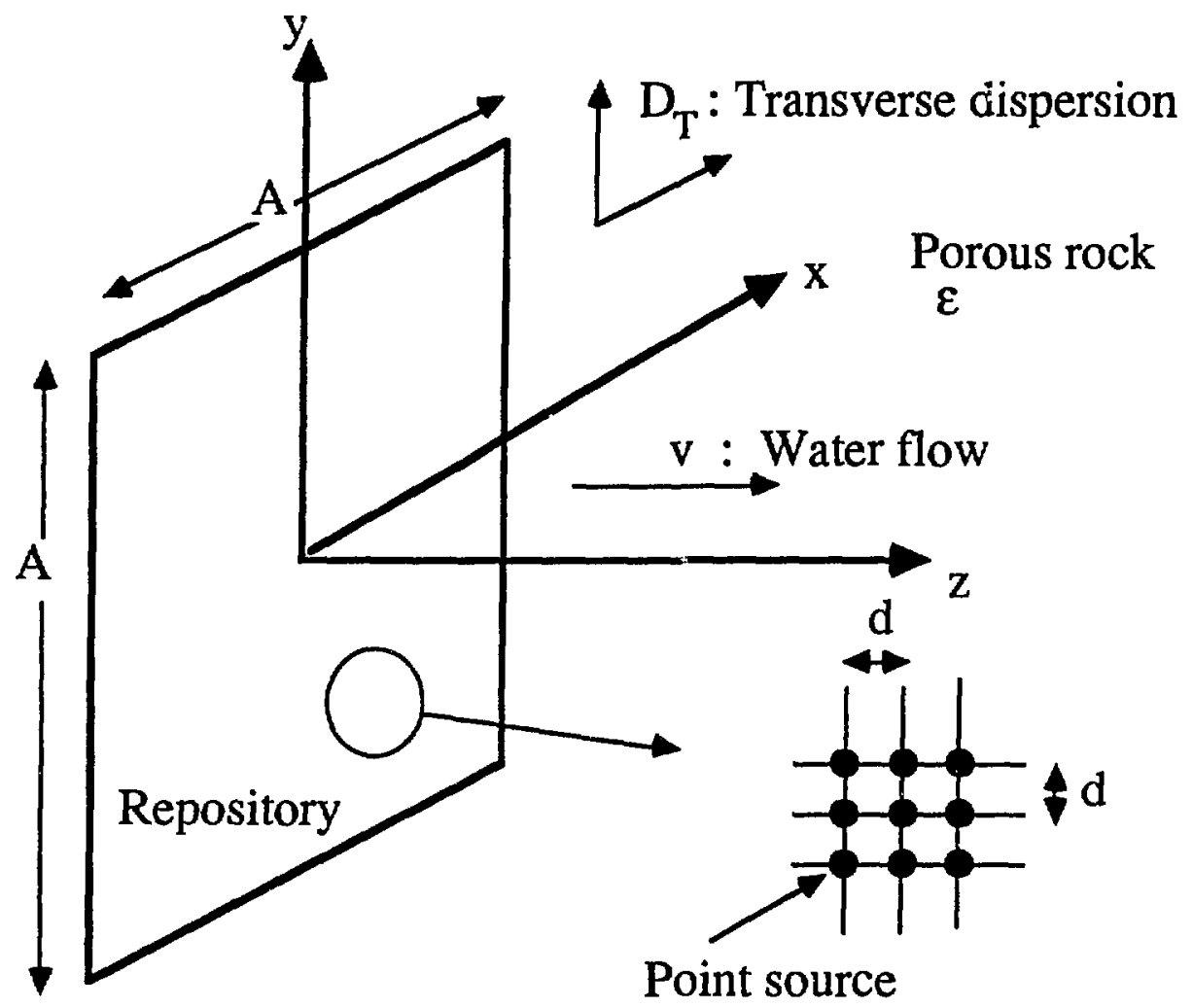

Figure 13 The Geometry for the problem of the Porous-media transport 
The analytical solution for a point source with transverse dispersion was first obtained. This solution was used for obtaining the solution for an array of point sources with transverse dispersion by superposition. The plane source of dimensions $d^{2}$ which has an equivalent strength to a point source was obtained in a similar way to that described in Section 4.1. By connecting infinitely many plane sources of equivalent strength, an infinite plane source of equivalent strength was defined. Then the ratio of the concentration resulting from an array of point sources to the concentration resulting from an infinite-plane source of an equivalent strength was taken to clarify the effect of transverse dispersion. The ratio has the form of:

$$
\frac{N^{2}(x, y, z, t)}{N^{\infty}(z, t)}=\frac{\varepsilon d^{2}}{4 \pi \theta^{2}} \sum_{k=1}^{m} \sum_{j=1}^{n} \exp \left[-\frac{\left(x-x_{k}\right)^{2}+\left(y-y_{j}\right)^{2}}{4 \theta^{2}}\right],
$$

where $N^{2}(x, y, z, t)$ is the concentration resulting from an array of point sources, $N^{\infty}(z, t)$ the concentration resulting from an infinite-plane source, $\theta$ the distance parameter defined in (3.6). $\left(x_{k}, y_{j}\right)$ are the coordinates of point source location. There are $m$ point sources on the $x$-coordinate and $n$ point sources on the $y$-coordinate. The factor consisting of $\varepsilon, d$, and $\theta$ ahead of the double summation comes from the ratio of the initial concentration at $z=0$ resulting from a point source to the initial concentration at $z=0$ resulting from an infiniteplane source.

Equation (4.12) can be compared with (4.10), which is for transport in a fractured medium. Both formula have a very similar structure; (4.12) contains an exponential function under the summation while (4.10) contains two error functions. This is because the ratio (4.12) is taken for point sources while the ratio (4.10) for patch sources. Eq. (4.10) can be rewritten in integral form:

$$
\frac{M(x, y, z, t ; m)}{M^{\infty}(y, z, t)}=\frac{d}{2 a \sqrt{\pi}} \sum_{k=1}^{m} \int_{\xi-\alpha}^{\xi+\alpha} e^{-t^{2}} d t \text {, where } \xi=\frac{x-x_{k}}{2 \theta} \text { and } \alpha=\frac{a}{2 \theta} .
$$


Figure 14, taken from Reference 3, shows results for the porous-media analyses. Comparing Figure 14 with Figure 9, we can make several observations. First, there are three regions for the distance parameter $\theta$. Second, the $\theta$ values dividing the three regions are almost equal. In fact in Figure 9, the peak and valley branches coincide at $\theta=3 \mathrm{~m}$, the same as in Figure 14. The $m=10,20,40$, and 80 cases in Figure 9 correspond to the arrays $10 \times 10$, $20 \times 20,40 \times 40$ and $80 \times 80$ in Figure 14, respectively. For each pair the ratio starts to deviate from unity at approximately the same $\theta$ values. For example, in Figure 9 , for $\mathrm{m}=10$ the curve starts to deviate from 'nnity at $\theta$ slightly larger than 10 . In Figure 14 , the $10 \times 10$ array case shows that the curve also becomes smaller than unity at $\theta$ approximately equal to 10 m.

This observation implies that multiple-patch sources which we have investigated in the preceding sections have a behaviour very similar to multiple-point sources. In the analytical solution (4.13) this can be explained as follows. Since the width $2 a$ of a patch source is very small compared with the pitch $d$ (we took $a=0.14 \mathrm{~m}$ and $d=10 \mathrm{~m}$ ), for a relatively large $\theta$ the integration interval in (4.13) becomes very small so that we can approximate the integral as follows:

$$
\int_{\xi-\alpha}^{\xi+\alpha} e^{-t^{2}} d t=\frac{a}{\theta} \cdot e^{-\xi^{2}}, \text { where } \xi=\frac{x-x_{k}}{2 \theta} \text { and } \alpha=\frac{a}{2 \theta} \text {, }
$$

Substituting (4.14) into (4.13) and comparing with (4.12), we can immediately see the similarity between (4.12) and (4.13) for a relatively large $\theta$. 


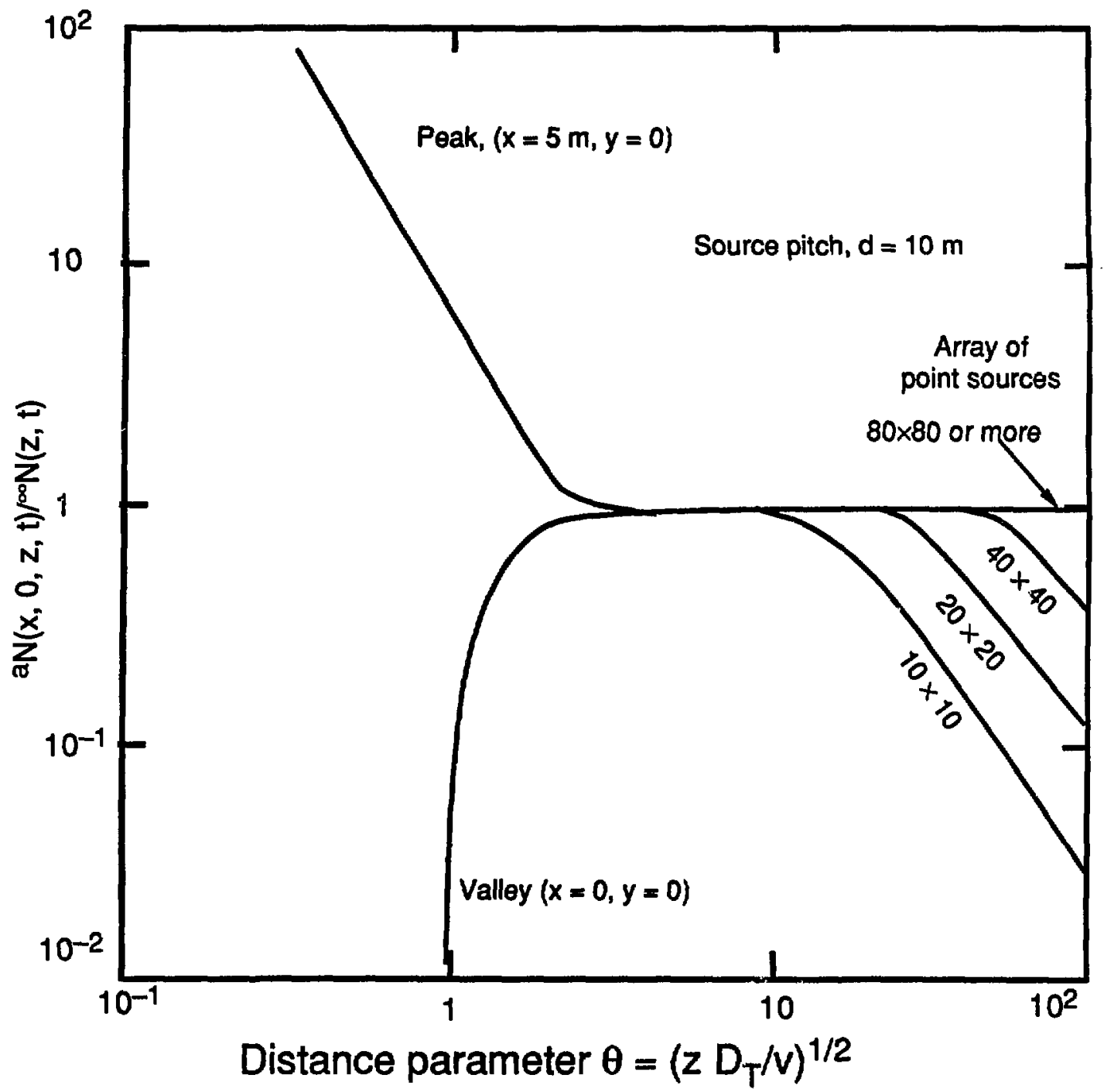

Figure 14 Relative nuclide concentration as a function of thr distance parameter for an array of point sources at $\mathbf{y}=0$ for a porous medium 


\section{Concluding Remarks}

In this report we presented analytic solutions for nuclide concentration fields resulting from nuclide released into a planar rock fracture from single and multiple patch sources. The governing equations considered

advection,

trnsverse dispersion in the fracture,

sorption on fracture walls,

matrix penetration by molecular diffusion,

sorption in rock pores, and

radioactive decay.

From aralyses on the single-patch solution, we can obtain the following insights:

(i) At a large downstream distance the concentration in the fracture shows a broad profile along the transverse direction. The gradient along the transverse axis is quite small. This is quite different from the behaviour of molecular diffusion into the rock matrix. At a large downstream distance the gradient along the axis into the rock matrix is very steep, but matrix penetration by molecular diffusion is yet very shallow.

(ii) Transverse dispersion attenuates the concentrations significantly both in the fracture and in the reck matrix, but has no significant effect in retarding the movement of the leading advection edge. This is also quite different from molecular diffusion into the rock matrix, which retards the movement of the advection edge significantly.

(iii) Back diffusion phenomena have been observed in the case of non-zero transverse dispersion. After the leach time, in the vicinity of the fracture entrance the radionuclide in the rock matrix diffuses out to the fracture, while at a further downstream point nucliife in the fracture diffuses into the rock matrix.

To compare the concentration resulting from multiple-patch sources with an infinite source or with an equivalent single-patch source, equivalent source strength has been defiried. Comparing the multiple-patch concentration with the infinite-source or the equivalent-single- 
patch concentration, we can distinguish three regions using the distance parameter $\theta=\left(z D_{T} /\right.$ v) $)^{1 / 2}$ :

Applicable Solutions

\begin{tabular}{llll}
\cline { 2 - 4 } Patch separation & multiple-patch & infinite-source & equivalent patch \\
\hline $10 \mathrm{~m}$ & $\theta \leq 3 \mathrm{~m}$ & $3 \leq \theta \leq \theta_{\mathrm{c}}$ & $\theta_{\mathrm{c}} \leq \theta$ \\
$5 \mathrm{~m}$ & $\theta \leq 1.5 \mathrm{~m}$ & $1.5 \leq \theta \leq \theta_{\mathrm{c}}$ & $\theta_{\mathrm{c}} \leq \dot{\theta}$ \\
\hline
\end{tabular}

where $\theta_{c}$ depends upon the number of patches. This table is valid for any nuclides, rock, time, and transverse distance in the region projected $\mathrm{m}$-patch area. Close $: 0$ the individual patch sources, plumes produced from multiple-patch sources are isolated from each other, and we must use the multiple-patch solution for evaluation of the concentration field. In a midregion due to locai transverse aispersion the plumes merged to one overall plume, and both the infinite-source and the equivalent-source approximation give identical results. At large distances downstream region the overall plume spreads out due to overall transverse dispersion. In the far field we can consider a cpository as a single patch source for prediction of the resulting radionuclide concentration field.

The results presented here are similar to previously published results for point-source arrays in porous media. The size of patch sources used in the current analysis is small comparial to the separation latween patches.

This report provides analytic solutions for peiformance assessment of nuclear waste repositories $_{\mathrm{r}}$ as well as insights into simplifying approximations which are vaiid. 


\section{References}

1. Ahn, J., P. L. Chambre, and T. H. Pigford, "Nuclide Migration Through a Planar Fissure With Matrix Diffusion," LBL-19429, April 1985.

2. Chambre, P. L., T. H. Pigford, A. Fujita, T. Kanki, A. Kobayashi, H. Lung, D. Ting, Y. Sato, and S. J. Zavoshy, "Analytical Performance Models For Geologic Repositories," Chapter 5, LBL-14842, October 1982.

3. Pigford, T. H., P. L. Chambre, M. Albert, M. Foglia, M. Harada, F. Iwamoto, T. Kanki, D. Leung, S. Masuda, S. Muraoka, and D. Ting, "Migration of Radionuclides Through Sorbing Media: Analytical Solutions - II," Chapter 4, LBL-11616, October 1980.

4. Ahn, J., P. L. Chambre, T. H. Pigford, "Nuclide Migration Through a Planar Fracture and Back Diffusion Phenomena," September 1986.

5. NAG library Mark 10, Numerical Algorithm Group 